\section{Screening for abdominal aortic aneurysms}

EDITOR, - P L Harris concludes his review of the issues concerning screening for abdominal aortic aneurysms by advocating a national screening programme.' We suggest that more caution is required because current evidence is inadequate to permit judgments on the merits of screening.

The rate of detection of patients with an aneurysm who would benefit from intervention might be extremely low. The prevalence of aneurysms among men in their late 60 s and early 70 s is roughly $2 \%$, but the prevalence of large aneurysms, which are in most danger of rupturing, is much less. Among 4331 subjects in four recent surveys only seven $(0 \cdot 16 \%)$ had an aneurysm $>6$ $\mathrm{cm}$ in diameter and $36(0.83 \%)$ had an aneurysm of $4.5-5.9 \mathrm{~cm}$ in diameter. ${ }^{2.5}$ Most surgeons would operate on aneurysms $>5.5 \mathrm{~cm}$ and observe those $<4.0 \mathrm{~cm}$. Disagreement on whether to operate on those of $4 \cdot 0-5 \cdot 5 \mathrm{~cm}$ will not be resolved until the results of the United Kingdom small aneurysm trial are available. Given current surgical practice, only about $15-20 \%$ of aneurysms $>3.0 \mathrm{~cm}$ detected on screening would be sufficiently large to warrant early surgery.

Many smaller aneurysms may expand so that surgery is justified later, but a major problem in deciding whether to detect smaller aneurysms is that the growth and rupture rates of aneurysms $<5.5 \mathrm{~cm}$ in the general population are not well established. The one follow up study quoted by Harris $^{6}$ reflects a general deficiency in this field: follow up studies are based on selected hospital patients or are too small to provide answers within reasonable confidence intervals. It could be that small aneurysms in the community are not worth detecting because the risks of growth, rupture, and death are slight in relation to the hazards of surgery, the cost of repeated ultrasound examinations, and anxiety for the patient.

To determine the need for a screening programme, information is required on the expected increase in life expectancy and the quality of the added years. Attempts to find out whether screening is beneficial by amalgamating the results of studies, including by use of computer simulation techniques, ${ }^{7}$ rely on too many assumptions - for example, that the study populations and measurement techniques are comparable. What is needed is to build on the information on feasibility, compliance, and detection rates provided by screening surveys ${ }^{2.5}$ and to conduct a randomised controlled trial comparing screening and unscreened populations. The costs and benefits of mounting a national screening programme would then have to be weighed up against other priorities in the health service.

F G R FOWKES

C V RUCKLEY

Wolfson Unit for Prevention of

Peripheral Vascular Diseases,

University of Edinburgh,

Edinburgh EH8 9AG

J T POWELL

Department of Surgery,

Charing Cross Hospital,

London W6 8RF

1 Harris PL. Reducing mortality from abdominal aortic aneurysms: need for a national screening programme. BMF 1992;305:6979. (19 September.)

\section{Advice to authors}

Priority will be given to letters that are less than 400 words long and are typed with double spacing. All authors should sign the letter. Please enclose a stamped addressed envelope for acknowledgment.

2 Collin J, Araujo L, Walton J, Lindsell D. Oxford screening programme for abdominal aortic aneurysm in men aged 65 to 74 years. Lancet 1988 ;ii:613-5.

3 Scott RAP, Ashton HA, Kay DN. Routine ultrasound screening in management of abdominal aortic aneurysm. BMF 1988;296: 1709-10.

4 O'Kelly TJ, Heather BP. General practice based population screening for abdominal aortic aneurysms: a pilot study. Brf Surg 1989;76:479-80.

5 Akkersdijk GJM, Puylaert JBCM, de Vries AC. Abdominal aortic aneurysm as an incidental finding in abdominal ultrasonography. Br F Surg 1991;78:1261-3.

6 Szilagyi DE, Elliot JP, Smith RF. Clinical fate of the patient with Szilagyi DE, Eliot JP, Smith RF. Clinical fate of the patient with
asymptomatic abdominal aortic aneurysm and unfit for asymptomatic abdominal aortic aneurysm
surgical treatment. Arch Surg 1972;104:600-6.

7 Bergqvist D, Bengtsson H. Is screening for abdominal aortic aneurysm worthwhile? Ann Chir Gynaecol 1992;81:203-8.

EDITOR, - P L Harris recommends establishing a mass screening programme for abdominal aortic aneurysm. ${ }^{1}$ We recently evaluated such a proposal for Dudley and South Birmingham Health Authorities and concluded that it is not appropriate to fund such a programme at present.

The evidence of benefit from screening is drawn primarily from an economic analysis by Collin, ${ }^{2}$ a study that is unsatisfactory in both its interpretation of published work and economic methodology. The key determinant in the benefit of screening for abdominal aortic aneurysm is the additional life expectancy of a screened cohort compared with a non-screened one: the values obtained by Collin cannot be supported by the published work. The limited evidence available suggests that life expectancy after elective repair of an aneurysm is shorter than that of an equivalent normal population ${ }^{3+}$ owing to considerable comorbidity. ${ }^{5}$ In addition Collin's analysis makes no reference to discounting of costs and benefits incurred over time.

A recent study, based on a thorough review of the available evidence, showed that there was no net increase in life expectancy between cohorts (J M Mason et al, health economics study group, $\mathrm{St}$ Andrews, Scotland, June 1992). It was concluded that much better information was required on the annual rate of rupture of aneurysms, how this rate varies with age, and the survival prospects of patients after elective and emergency resection. Although Harris quotes a rupture rate of $7 \%$ a year for aneurysms of $5.5 \mathrm{~cm}$ or over, other evidence suggests that it may be much lower. ${ }^{67}$ Most of the rupture rates have been derived from follow up of people not fit for surgery, who are at greater risk than a true control group.

To say that the aetiology of abdominal aortic aneurysm is uncertain ignores much evidence indicating that the condition shares major risk factors with arterial disease in general, ${ }^{89}$ in particular smoking and hypertension. Resources to add years of life ${ }^{10}$ may be more appropriately used in primary prevention, with the possibility of an additional impact on major causes of death such as ischaemic heart disease and stroke.

Given the uncertainties discussed above, establishing mass screening for abdominal aortic aneurysm is inappropriate at present. Properly conducted randomised controlled trials are needed to resolve these uncertainties; they could also study groups at higher risk of rupture such as hypertensive subjects. Only then will we have sufficient knowledge to make an informed decision about the risks and benefits of such a programme.

Centre for Health Economics,

J M MASON

York University,

Dudley Health Authority,

A WAKEMAN

Dudley DY1 2DD

Institute of Public and Environmental Health,

Birmingham Medical School

Birmingham B152\%T

1 Harris PL. Reducing the mortality from abdominal aortic aneurysms: need for a national screening programme. BMY

2 Collin J. The value of screening for abdominal aortic aneurysm by ultrasound. In: Greenhalgh RM, Marrick JA, eds. The cause and management of aneurysms. London: Saunders, 1990.

3 Soreide O, Lillestol J, Christiensen O, Grimsgaard C, Myhr HO, Solheim K, et al. Abdominal aortic aneurysms: survival analysis of four hundred thirty-four patients. Surgery 1982; 91:188-93.

4 Nachbur E, Gut A, Sigrist S. Prognostic factors in the surgical treatment of aorto-iliac aneurysmal disease. 7 Cardiovasc Sury 1987;28:469-78.

5 Hertzer NR, Beven EG, Young JR, O'Hara PJ, Ruschhaupt WF III, Graor RA, et al. Coronary artery disease in peripheral vascular patients. A classification of 1,000 coronary angiovascular patients. A classification of 1,000 coronary angiograms and $\mathrm{r}$

6 Nevitt MP, Ballard DJ, Hallett JW Jr. Prognosis of abdominal aortic aneurysms. N Engl f Med 1989;321:1009-14.

7 Guirgis EM, Barber GG. The natural history of abdominal aortic aneurysms. Am $\mathcal{F}$ Surg 1991;162:481-3.

8 Allen PIM. Screening for abdominal aortic aneurysm. Biomed Pharmacother 1988;42:451-4.

9 Thurmond AS, Semler HJ. Abdominal aortic aneurysm: incidence in a population at risk. $\mathcal{F}$ Cardiovasc Surg 1986;27 $457-60$.

10 Secretary of State for Health. The health of the nation: a strategy for health in England. London: HMSO, 1992.

EDITOR,-P L Harris makes a compelling case for setting up a national screening programme for abdominal aortic aneurysms.' A high risk group not mentioned in the article is patients with hypertension. In this group the single screening scan at 65 for men only that Harris suggests would not be adequate. We briefly report our experiences in screening a general practice population of hypertensive patients to support this claim.

Over the past 18 months in Mid-Glamorgan we have screened 851 hypertensive patients ( 463 men, 388 women) drawn from the registers of three local group practices. The mean age of these patients at screening was 63.5 years. In the 463 men 36 aneurysms were found, of which 12 were over $3.5 \mathrm{~cm}$, giving an overall incidence of $7.8 \%$ and an incidence of aneurysms over $3.5 \mathrm{~cm}$ of $2.6 \%$. In the 216 men aged 65 and over, however, the incidence rose to $10.6 \%$ (23 aneurysms; seven $(3 \cdot 2 \%)$ aneurysms over $3.5 \mathrm{~cm})$. In the 247 men under 65 the incidence of aneurysms was $5 \cdot 3 \%$ (13 aneurysms) and five $(2.0 \%)$ of these men had aneurysms over $3.5 \mathrm{~cm}$. Eight men had elective repairs of the aneurysm as a result of ultrasound screening, and the remainder are having regular repeat scanning.

Little is known about the natural course of aneurysms in hypertensive patients. Three of our patients requiring elective repair were under 65 
$(61,62$, and 63). Also, three of our patients who were operated on had small aneurysms initially that grew by over $1 \mathrm{~cm}$ in six months, a far quicker rate of growth than that described by others in nonhypertensive patients.

On the basis of our initial findings we believe that screening should be offered to male hypertensive patients from the age of 60 and should be done regularly - for example, every three to five years - in this group

In the 388 women we have screened eight aneurysms have been detected (only two over $3.5 \mathrm{~cm}$ ), confirming the low incidence of aneurysms in women described by others. ${ }^{3}$ One woman, aged 72 , has required an elective repair of an aneurysm of $6.1 \mathrm{~cm}$. Many more hypertensive women will require screening to determine more precisely the lower incidence of aneurysms in this group. Offering screening in some form to this group may well, however, prove to be just as economical as breast cancer screening, in terms of quality adjusted life years at least.

Numerous studies have suggested an association between hypertension and abdominal aortic aneurysms. We believe that hypertensive people also "require special provision for screening irrespective of any plans to screen apparently healthy people."'

MARTIN SOWTER MICHAEL LEWIS

Department of Surgery,

East Glamorgan Hospital,

Pontvpridd,

Mid-Glamorgan CF38 $1 \mathrm{AB}$

1 Harris PL. Reducing the mortality from abdominal aortic aneurysms: need for a national screening programme. $B M$. aneurysms: need for a national

2 Delin A, Ohlsen H, Swedenborg J. Growth rates of abdomin ortic aneurysms as measured by computed tomography. $\mathrm{Br}$ Surg 1985;72:530-2.

3 Collin J. The epidemiology of abdominal aortic aneurysms. $\mathrm{Br}$. Hosp Med 1988;39:64-7.

EDIToR, - I am sympathetic to P L Harris's objective of trying to reduce mortality from ruptured abdominal aortic aneurysms.' I have recently screened $678(97.6 \%)$ of the 695 patients aged $60-79$ in our practice for aneurysms. Twenty six were found to have an aneurysm (range $3 \cdot 0-8 \cdot 3 \mathrm{~cm}$ external sagittal diameter), and 13 were referred for a surgical opinion. The screening programme has exposed some of the dilemmas in current management of aneurysms.

Patients deserve to know of important risks associated with repair of an aneurysm. Harris's statement that in the best centres elective repair carries an "operative risk of under 5\%" cannot be generally assumed, and published mortality statistics may not reflect the risk for an average patient. ${ }^{2}$ Morbidity associated with elective repair of an aneurysm has not been widely published, bu in series of mixed elective and emergency repairs it has been considerable. ${ }^{3-5}$ Without reference statistics on mortality and morbidity the balance of when to operate for a particular size of aneurysm and risk to the patient becomes uncomfortably difficult. For individual patients local results will be most pertinent unless distant referral is considered.

Harris rightly directs attention to aneurysms of $4 \cdot 0-5 \cdot 0 \mathrm{~cm}$, for which management is contentious most aneurysms detected by screening fall into this category. Surgery has been advocated for aneurysms of $>4 \mathrm{~cm},{ }^{6}$ but such an aggressive policy is not supported by recent prospective ${ }^{7 \times}$ and retrospective" studies of the natural course of aneurysm. Rarely, small aneurysms will rupture fatally, but I believe that relatives find unlikely natural tragedy easier to bear than tragedy after well intentioned surgery. A more conservative approach to surgery tips the risk-benefit balance towards benefit, and Scott $e$ t al's study exemplifies how such a policy has worked successfully.?

With regard to the psychological consequences of detecting aneurysms by screening, will patients with small aneurysms be able to maintain a fair perspective of a low risk of rupture or will their predominant perception be of a time bomb waiting to explode within? The predicament of those with large aneurysms who are considered to be unfit for surgery is particularly unfortunate. The anxiety an aneurysm can generate should not be underestimated or disregarded.

If a low mortality and morbidity associated with elective surgery, a conservative approach to intervention, and adequate counselling of patients can be combined then I believe that a local screening policy for aneurysms could make good ethical and economical sense. That such criteria apply nationally is doubtful, and currently I do not favour a national screening programme.

Lastly, $\beta$ blockade has shown promise in the management of aneurysms." As aneurysms are common, whether physiological $\beta_{1}$ adrenergic antagonism can retard their expansion or reduce the rate of rupture is of great practical importance. An extension of the Medical Research Council's small aneurysm study to address this issue would be expedient.

J S ROSE

The Surgery

Lindford,

Hampshire GU35 0OJ

1 Harris PL. Reducing the mortality from abdominal aortic aneurysms: need for a national screening programme. $B M \mathcal{F}$ 1992;305:697-9. (19 September.)

Vella V, Shandall A, Duthie G, Shute K. Aortic aneurysms who should do them? Ann R Coll Surg Engl 1990;72:215-7.

3 Giorgetti PL, Arpesani A, Bortolani EM, Rampoldi V, Rignano $\mathrm{A}$, Ghildardi $\mathrm{G}$, et al. Abdominal aortic aneurysm surgery in A, Ghildardi G, et al. Abdominal aortic aneurysm surgery in
over 75 year old patients. Panminerva Med 1991;33:19-25.

4 Branchereau A, Nazet J, Colavolpe J, Scotti L. Combined mortality and morbidity of direct surgical treatment of abdominal aortic aneurysms. Ann Vasc Surg 1990;4:10-4.

5 Olsen P, Schroeder T, Agerskov K, Røder O, Sorensen S, Perko $M$, et al. Surgery for abdominal aortic aneurysms. f Cardiovasc Surg 1991;32:636-42.

6 Collin J. Point of view. Elective surgery for small abdominal aortic aneurysms. Lancet 1987;i:909.

Scott RAP, Ashton HA, Kay DN. Abdominal aortic aneurysm in 4237 screened patients: prevalence development and management over 6 years. Br $\mathcal{F}$ Surg 1991;78:1122-5.

8 Guirguis EM, Barber GG. The natural history of abdominal aortic aneurysms. Am F Surg 1991;162:481-3.

9 Nevitt MP, Ballard DJ, Hallett JW. Prognosis of abdominal aortic aneurysms. N Engl f Med 1989;321:1009-14.

10 Leach SD, Toole AL, Stern H, De Natale RW, Tilson MD. Effect of $\beta$-adrenergic blockade on the growth rate of abdominal aortic aneurysms. Arch Surg 1988;123:606-9.

\section{Domiciliary thrombolysis by general practitioners}

EDITOR,-The results of the Grampian region early anistreplase trial' need to be seen within the context of the burden of myocardial infarction that is carried by a community. The general practitioners who participated clearly, and effectively, performed a great deal of selection. Recruitment of one patient every 11 months means that most patients with myocardial infarction were not entered into the trial. A local estimate for Plymouth Health Authority is of eight to 10 myocardial infarctions per general practitioner each year; on the basis of the lower figure, and assuming a $30 \%$ death rate if medical help is not called, these general practitioners' patients would have suffered 1537 myocardial infarctions, but only 311 were recruited.

Another way of looking at this is to consider the total number of deaths ascribed to myocardial infarction among patients of the doctors in the study. Extrapolation from local data for Plymouth gives an estimate of 1060 deaths over the period of the study. A considerable proportion of these will have been sudden deaths; this still leaves many more deaths than those noted during the study.

Any strategy for implementing a new advance needs to take into account the whole range of presentations of conditions; for thrombolysis this means not only patients with classical myocardial infarction diagnosed by general practitioners but also, for example, people with atypical chest pain and those who do not perceive their symptoms as serious.

Plymouth Health Authority

ALISON ROUND Plymouth PL6 5XN

1 GREAT Group. Feasibility, safety, and efficacy of domiciliary thrombolysis by general practitioners: Grampian region early anistreplase trial. $B M \mathcal{F}$ 1992;305:548-53. (5 September.)

EDITOR, - I am surprised that in the Grampian region early anistreplase trial no patients were diagnosed as having unstable angina, which is the most common differential diagnosis and the most difficult to make in the early stages of a myocardial infarction.' It is likely that the patients in the diagnostic groups "possible myocardial infarction" and "ischaemic heart disease" in fact had unstable angina. If only definite and probable myocardial infarctions are counted the diagnostic accuracy of the general practitioners was $57 \%$ (and of the hospital doctors $66 \%$ ). This may also account for the lower mortality and fewer $Q$ wave infarctions in the domiciliary group.

As there is no evidence that thrombolytic treatment is of benefit in unstable angina ${ }^{2}$ it seems that nearly half the patients in the study received thrombolytic treatment inappropriately and were needlessly exposed to the risks of haemorrhage. Colleagues and I found similar figures in a study in Somerset, where the general practitioners accurately diagnosed myocardial infarction on clinical grounds (without electrocardiography in most cases) in $45 \%$ of cases (S Rule et al, unpublished work). Again this was largely because many patients with unstable angina were thought to be in the early stages of myocardial infarction.

Diagnosing myocardial infarction at the onset can be difficult, but at a minimum a good history should be obtained and an electrocardiogram properly interpreted. In the Grampian study the general practitioner was required to record an electrocardiogram but not to interpret it, which seems pointless. It is the electrocardiogram, however, that causes problems for many general practitioners as individually they will see few cases of myocardial infarction each year. The higher diagnostic accuracy in hospital may relate to this.

Taunton and Somerset Hospital,

JOHN E SANDERSON

Taunton,

Somerset TA1 5DA

GREAT Group. Feasibility, safety, and efficacy of domiciliary thrombolysis by general practitioners: Grampian region early anistreplase trial. BMf 1992;305:548-53. (5 September.)

2 UNASEM Collaborative Group. Thrombolytic agents in unstable angina. $\mathcal{f}$ Am Coll Cardiol 1990;15:65 A.

EDITOR, - The Grampian region early anistreplase trial provides a valuable contribution to the debate on pre-hospital thrombolysis, particularly in view of the importance of minimising the delay to treatment.' ${ }^{\prime}$ Several points merit additional discussion. Although the authors state that about $60 \%$ of eligible patients were recruited into the study, they do not state the proportion of all patients with myocardial infarction. The narrow time window for entry to the trial selected patients presenting early. Indeed, the median patient delay in an earlier community study by the same authors was two hours, ${ }^{2}$ compared with 45 minutes in this study. Thus the improvements in outcome may not necessarily apply to patients presenting later. The median delay to presentation in recent large scale studies has been substantially longer $(57 \%$ beyond four hours in the second international study of infarct survival ${ }^{3}$ ).

The high accuracy of diagnosis achieved in this 